\title{
Urdimento
}

\section{A ENCENAÇÃO DO DRAMA WAGNERIANO}

\author{
Adolphe Appia \\ Tradução de José Ronaldo Faleiroº
}

Estas poucas páginas talvez pareçam, a quem se der o trabalho de lê-las, excessivamente concisas, e, consequentemente, considerando a natureza do tema, um pouco obscuras. Mas não sabendo se terei algum dia a ocasião de publicar a série bastante considerável de trabalhos que o tema comporta, quero pelo menos ter apresentado uma espécie de sumário deles.

Compreender-se-á que se trata muito menos, aqui, dos dramas de Richard Wagner em particular, do que das condições de equilíbrio da forma de drama criada por ele. Essas condições possuem, é claro, uma importância artística considerável, e este estudo tem como finalidade resumi-las; não é, porém, a única finalidade que persigo.

Que uma arte de um alcance tão geral não tenha podido encontrar em nossa cultura atual os meios mais elementares de viver e de se manifestar, aí está um sintoma significativo da falta absoluta de harmonia que domina as nossas faculdades receptivas em relação a uma obra de arte. Ademais, qualquer esforço que for tentado para reconstituir a harmonia nativa dessas faculdades adquirirá um alcance muito mais amplo do que poderia parecer à primeira vista; e a minha única esperança ao publicar este pequeno trabalho é, portanto, chamar a atenção para essas questões, $e$ acelerar assim, talvez, um ensaio prático de representação normal, o único que seria capaz de provocar a convicção junto a um público esclarecido.

A.A.

\section{Noções preliminares}

Wagner criou uma nova forma de drama ${ }^{3}$. Em seus escritos teóricos, fixou definitivamente o que se pode denominar as condições abstratas dele. A aplicação que apresentou dessas novas formas nos seus dramas parece subentender como resolvidas as condições representativas. Ora, não é o caso; e um grande número de equívocos e de dificuldades acumulados contra essa obra de arte se originam na desproporção entre os meios que o autor utilizou para a notação do drama, e aqueles que ele encontra, no estado atual da

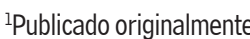
em APPIA, Adolphe. La mise en scène du drama wagnérien. Notions préliminaires [A Encenação do Drama Wagneriano. Noções Preliminares], p. 260-266, notas p. 443-445, in

Euvres Complètes

[Obras Completas]. Édition élaborée et commentée par

Marie L. Bablet-Hahn. Introduction générale par Denis Bablet Edição elaborada e comentada por Marie L. Bablet Hahn. Introdução por Denis Bablet]. Tome I, 1880-1894. Lausanne: L'Âge d'Homme, 1983. As notas do editor francês foram aqui suprimidas (N. do T.). ${ }^{2}$ Professor do Departamento de Artes Cênicas e do Programa de PósGraduação em Teatro do CEART/UDESC,

Bacharel e Licenciado em Artes Cênicas pela UFRGS, Mestre pela Universidade de Paris III-Sorbonne e Doutor em Teatro pela Universidade de Paris X-Nanterre. 


\section{Urdimento}

${ }^{3}$ Ele a designa em alemão pela palavra Wort-Tondrama, o que significa um drama no qual 0 poeta utiliza a palavra e o som musical. Esse tipo de drama é, de certo modo, a síntese do Wortdrama, o "drama em palavras", ou seja, drama falado, e do Ton-drama, 0 único "drama musical" verdadeiro, no qual o poeta só emprega a música, como Beethoven em Coriolano, na Sinfonia Heróica, etc., Berlioz na Sinfonia Fantástica, Liszt nos Poemas Sinfônicos. Nunca é demais lembrar que Wagner protesta formalmente contra o termo "drama musical" aplicado às suas obras de teatro. Como a língua francesa não se presta a um equivalente de Wort-Tondrama, direi "drama wagneriano" ou "drama do poetamúsico". Peço apenas que se dignem observar que por "drama wagneriano" não entendo designar exclusivamente os dramas de Richard Wagner, mas, em geral, a nova forma criada por ele. encenação, para a sua realização. Não falo aqui sequer das novas exigências impostas por esse drama aos intérpretes: elas são evidentes.

Há, portanto, um vazio para preencher. No entanto, ao olhar mais de perto, percebe-se que se trata, sobretudo, de uma arrumação, e que todos os elementos para ordenar são fornecidos tacitamente pelo próprio drama.

A continuação destas páginas esclarecerá o que essas afirmações podem ter de paradoxal. Para evitar lembrar com excessiva frequência o ponto de vista em que me situo, e atenuar certas durezas necessárias nos argumentos, devo dizer que esse ponto de vista é exclusivamente o do encenador, o qual, embora dê vida à obra de arte, de modo algum toca no fato desta obra.

É o Drama falado, e não a ópera, que deve fornecer o ponto de partida. O que distingue o drama wagneriano do drama falado é o emprego da música. Ora, a música não somente dá ao drama o elemento expressivo: ela também fixa peremptoriamente a duração. Pode-se afirmar, portanto, que do ponto de vista representativo a música é o Tempo; e não compreendo por isso «uma duração no tempo», mas o próprio Tempo. Ela dá, consequentemente, as dimensões: primeiro as proporções coreográficas em sequência, desde os movimentos de multidão até os gestos individuais; depois, a partir daí, com maior ou menor insistência, as proporções do quadro inanimado.

No drama falado, é a vida que fornece aos intérpretes os exemplos de duração (Tempo): o autor não pode fixar a da palavra, embora imponha um mínimo de exigências pela quantidade do texto; e a ação não dá precisão nem ao desenvolvimento das evoluções nem às proporções do cenário.

No drama do poeta-músico, ao contrário, a duração é rigorosamente fixada, e fixada pela música, que altera as proporções que a vida teria fornecido. Pois a maioria de nossos gestos acompanha a palavra, ou é palavra subentendida; e alterar a duração desta é alterar a duração daqueles. Além disso, a música, por natureza, precisa se desenvolver, de modo que as evoluções que a palavra (subentendida) não fixa, mas que a vida, por sinal, nos ensina, também são alteradas pela duração dos desenvolvimentos indispensáveis a esse meio de expressão, mas exteriores (como encenação) à vida dramática, e à qual se referem apenas vagamente, ou até distorcem.

Eis condições essencialmente diferentes das condições do drama falado. Se a ópera não houvesse vulgarizado a mudança na duração natural, não teria sido possível compor integralmente o drama wagneriano sem se preocupar com essa alteração capital.

Portanto, já não será a vida que dará aos intérpretes os exemplos de duração e de sequência, mas a música, que os impõe diretamente; e esta, 


\section{Urdimento}

alterando a duração da palavra, altera as proporções dos gestos, das evoluções, do cenário: assim, o espetáculo inteiro é transposto.

O que caracteriza o drama do poeta-músico e constitui o seu alto valor é o meio que possui, graças à música, de expressar o drama interior, enquanto o drama falado só pode significá-lo. Visto que a música é o Tempo, ela dá ao drama interior uma duração que deve corresponder a um espetáculo. $\mathrm{Na}$ vida, os movimentos da alma, do corpo e do espírito são simultâneos. Se a música expressasse os movimentos da alma por um simples acréscimo de intensidade, o problema (representativo) não existiria. Mas não é o caso; e disso resulta que à alteração na duração da palavra vem juntar-se essa coisa complexa da duração necessária à expressão do drama interior. Ora, considerando a natureza especial da música, o drama interior não consegue encontrar o lugar suficiente ao seu desenvolvimento nos exemplos de duração que a vida fornece ao drama falado.

É isso o que distingue definitivamente o drama wagneriano do drama falado, do ponto de vista prático do encenador, e sem entrar nas considerações de outra ordem que separam as duas formas desde a origem de ambas.

Trata-se, portanto, de um drama em que são alteradas todas as proporções de duração e de seqüência que a vida fornece ao drama falado, e ao qual vem acrescentar-se uma duração nova: a do drama interior, que a vida não lhe fornece (como duração) ${ }^{4}$. Portanto, os meios representativos do drama falado não conseguiriam servir a ele; e os da ópera, que pela sua duração seriam de uso cômodo, também devem ser descartados, por serem motivados apenas por um prolongamento arbitrário no tempo, sem necessidade dramática. Daí decorre que a encenação do drama wagneriano deve ser composta unicamente dos elementos que o drama wagneriano lhe fornece, e que é a técnica teatral (cujas condições atuais têm em vista apenas o drama falado e a ópera) que deve se conformar às novas exigências.

Será que algum dia tais exigências poderão ser fixadas? Não, por serem dependentes apenas do próprio drama, e por não se apoiarem nem numa convenção, como a ópera, nem na imitação mais ou menos fiel da vida, como o drama falado. Cada drama determina, pois, a sua encenação, e a técnica teatral propriamente dita serve aqui somente como limite flutuante, sem determinar nada.

A conclusão inevitável é que o drama do poeta-músico recai inteiramente no autor, e que este não pode esperar unidade, se a parte representativa (a direção [la régie ]) - cujas proporções (a duração), afinal de contas, ele fixa rigorosamente por meio da música - não entrar na própria concepção do drama. E aí reside o que opôs, e ainda opõe, dificuldades intransponíveis para
${ }^{4}$ Não entendo dizer com isso que a música não possa expressar simultaneamente 0 drama interior e a ação representativa; faço alusão apenas ao fato da duração do drama interior que exige cenas que ela possa preencher, e que pode também transbordar por um espetáculo vazio (espetáculo no sentido necessário ao drama falado). 


\section{Urdimento}

a manifestação dos dramas de Richard Wagner, e para a compreensão da idéia do drama novo, de que são a aplicação.

Só se pode, pois, tratar a encenação do drama wagneriano teoricamente, visto que os próprios princípios da encenação, para cada obra em particular, são determinados unicamente pela obra em si; e a parte abstrata dessa teoria, que forma o tema do presente capítulo, é forçosamente muito restrita, pois só pode levar em consideração as nossas exigências mais gerais de equilibro, sem ousar atribuir-se um objeto preciso.

Quando se fala de representação, supõe-se um público. A representação de um drama tem como finalidade unicamente convencer esse público da realidade da vida que anima esse drama.

Quem quiser convencer alguém se deixará guiar por todos os indícios que puder encontrar sobre as capacidades das pessoas a que se dirige. Se quisermos convencer o público atual da realidade do drama wagneriano, que indícios tal público nos fornecerá para nos guiar em nossa tarefa?

Primeiro, ele tem o gosto deturpado. Daí decorre que ele é fraco, o que o deixa numa grande passividade. Essa passividade se manifesta de várias maneiras: inércia para sair das formas aprovadas sem exame; impotência para suportar a intensidade musical; e, sobretudo, incapacidade de reunir as partes constitutivas do drama, ou, em outros termos, impotência de concentração.

Atenhamo-nos a essas três manifestações, que resumem bem a situação atual. A inércia para sair das formas aprovadas necessita que se apresente ao público o drama numa forma que não possa causar nenhum equívoco. A sua impotência para suportar a intensidade musical, impotência que o paralisa e lhe tira o uso dos outros recursos, obriga a dar ao espetáculo dos olhos uma intensidade correspondente, a qual possibilita que o espectador perceba todas as suas sensações. Quanto à impotência de concentração, ela já ficará sensivelmente diminuída, se conseguirmos realizar as duas condições precedentes; e quando a concepção representativa caminhar pari passu com a do próprio drama, a representação já pedirá ao espectador apenas os esforços de que ele facilmente for capaz.

Dessas três condições, só duas dependem de nós; a terceira (a concepção representativa que anda junto com a concepção do próprio drama) constitui um problema que tão-somente o dramaturgo pode resolver. No futuro, exclusivamente a ele, portanto, caberá a preocupação pelo equilíbrio da sua obra perante o público. Atualmente possuímos outros exemplos do drama wagneriano unicamente nos dramas do próprio Richard Wagner; e, como essa terceira condição que acabamos de indicar 
não foi preenchida por ele, conclui-se que as condições presentes do drama wagneriano não são as condições normais dessa obra de arte; e que, ao tratá-las, somos forçados a não considerar essas condições normais que permaneceram desconhecidas para nós. O problema dos procedimentos que encontrar para convencer o público atual é, portanto, duplamente delicado, e esse público tem direito a toda a deferência.

Dissemos que a sua fraqueza exigia uma forma representativa que afastasse o equívoco, e uma intensidade de espetáculo que correspondesse à intensidade da música. O que distingue do ponto de vista representativo o drama wagneriano do drama falado é que em vez de lançar mão da duração na vida, ele próprio a fixa rigorosamente: tão-só uma inteligência precisa desse fato fornecerá o caráter distintivo que não poderá deixar dúvida sobre a existência original do drama assim compreendido. Desse ponto de vista superior, o perigo da ópera desaparecerá completamente.

Para a intensidade do espetáculo, é necessário entrar em acordo sobre o sentido da palavra «intensidade» em matéria representativa: tratase da maior ou menor quantidade de gosto incluído na escolha do luxo decorativo, de uma pesquisa sutil de colorido, de violência ou de lirismo na mímica, etc.? Para um drama que não fixaria sozinho a duração (a sequência e as proporções), poderíamos hesitar: para o drama do poeta-músico, é nele mesmo que devemos encontrar toda e qualquer vida, é ele que dá essa vida, e qualquer intensidade que venha de fora permanece letra morta para o público, e, assim, deixa de existir, do ponto de vista dramático. Consequentemente, a maior ou menor intensidade representativa desse drama está na razão direta das relações mais ou menos adequadas da sua encenação com a vida dada pelo drama. Para o drama wagneriano do porvir, a responsabilidade caberá ao dramaturgo; atualmente é a nós que ela cabe, e a tarefa é pesada.

Vemos que nos resta uma única condição teórica que possamos fixar antes de toda e qualquer aplicação; e essa condição que devemos considerar como a base da encenação do drama wagneriano é que a vida nos é dada exclusivamente pelo próprio drama.

Portanto, em resumo: sendo a música o Tempo, ela dá as proporções; de tal maneira que a encenação do drama wagneriano já não tem que procurar os exemplos de duração na vida, mas que toda e qualquer vida se encontra fixada rigorosamente pelo próprio drama; daí resulta que esse drama recai inteiramente no dramaturgo, que cria, de certo modo, o Tempo e o Espaço, e que, possuindo o meio de justificar a sua criação, se torna o evocatório mais poderoso que exista. Como os dramas de Richard Wagner não preenchem essa condição, e são os únicos que possuímos do novo gênero, as condições 


\section{Urdimento}

atuais dessa obra de arte não são, pois, as suas condições normais. Se, contudo, quisermos convencer o público da vida original delas, a maneira de apresentálas a ele se torna uma questão muito delicada. Ora, ocorre que as condições impostas por esse público estão de acordo com a condição fundamental do drama wagneriano, a saber: que é apenas nesse drama que temos de encontrar a vida. Assim, o encenador dos dramas de Wagner deverá deixar-se guiar exclusivamente, servilmente, por tudo o que o drama que ele quer representar lhe revele da sua vida própria.

Portanto, ao fixar as condições abstratas do seu drama, Wagner fixava tacitamente as condições representativas deste, já que elas estão necessariamente contidas nele; e apenas na aplicação que deu a elas foi que deixou de perseguir rigorosamente a sua consequência. 
Urdimento

\section{NORMAS PARA PUBLICAÇÃO DE ARTIGOS}

A Revista Urdimento é uma publicação do Programa de PósGraduação em Teatro da Universidade do Estado de Santa Catarina e reúne artigos que contribuiem para a pesquisa na área das artes cênicas.

A Urdimento recebe as colaborações em fluxo contínuo que são analisadas pelo Conselho Editorial. As seguintes normas técnicas devem ser observadas para a publicação das contribuições.

1) Os artigos devem ter no mínimo 8 e máximo 12 laudas. Resenhas de livros entre 3 e 4 laudas. Os textos deverão ser digitados com letra Times New Roman, tamanho 12, com espaçamento 1,5 cm em Word para Windows (ou compatível).

2) Os colaboradores devem incluir dados especificando as atividades que exercem, a instituição (se for o caso) em que trabalham e dados básicos dos respectivos currículos.

3) Solicita-se clareza e objetividade nos títulos.

4) Os artigos devem vir acompanhados de resumo com no máximo de 6 linhas e 3 palavras-chaves, ambos com as respectivas traduções para o inglês.

5) $\mathrm{O}$ envio do artigo original implica na autorização para publicação, tanto na forma imprensa como digital da revista.

6) Notas explicativas serão aceitas desde que sejam imprescindíveis e breves. As citações no corpo do texto que sejam superiores a 5 linhas devem ser digitadas em espaço simples com tamanho 10 em itálico. As citações no corpo do texto devem seguir a formatação (AUTOR, 2008, p.1).

7) Todas as palavras em língua estrangeira devem estar em itálico.

8) As notas de rodapé devem ser apresentadas no fim de cada página e numeradas em algarismos arábicos.

9) Caso os artigos incluam fotos, desenhos ou materiais gráficos 


\section{Urdimento}

da autoria de terceiros, é indispensável carta de autorização. O material deverá vir acompanho de legendas de identificação. $\mathrm{O}$ material gráfico deve ser reduzido ao mínimo indispensável, em formato JPG e com resolução de 300 dpi, enviadas em arquivos separados do texto. Somente serão publicadas imagens em preto e branco.

10) O material para a publicação deverá ser encaminhado em duas vias impressas e uma em formato digital (programa word) para o e-mail urdimento@udesc.br aos cuidados da revista.

Endereço para correspondência e envio de colaborações:

\section{Revista Urdimento}

Programa de Pós-Graduação em Teatro - UDESC

Av. Madre Benvenuta, 1.907 - Itacorubi

88.035-001 - Florianópolis - SC

E-mail: urdimento@udesc.br

\section{Normas para citação de referência bibliográfica:}

\section{Livros}

SOBRENOME, Prenomes do autor. Título: subtítulo. edição. Local: editor, ano de publicação.

\section{Teses/ Dissertações/Monografias}

SOBRENOME, Prenomes do autor. Título: subtítulo. ano. $\mathrm{n}^{\circ}$ total de páginas.Tese, Dissertação ou Monografia (grau e área) - Unidade de Ensino, Instituição, Local e ano.

\section{Artigos de periódicos na internet}

SOBRENOME, Prenomes do autor. Título do artigo. Título da Revista, local, volume, número, páginas do artigo, mês e ano de publicação. Notas. Disponível em: <http://www....> Acesso em: dia mês (abreviado) ano, hora: minutos.

\section{Artigos}

SOBRENOME, Prenomes do autor do artigo. Título do artigo. Título da Revista, local, volume, número, páginas do artigo (inicial e final), mês e ano da publicação do artigo. 
Realização:

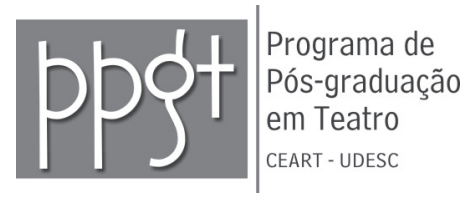

Programa de Pós-Graduação em Teatro

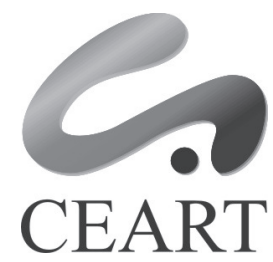

Centro de Artes 
Este projeto editorial foi criado eletronicamente utilizando o software Adobe In Design CS3. As famílias tipográficas Bell MT e BellCent são utilizadas em toda esta revista. 